\title{
Modeling And Simulation of A Grid Connected Hybrid Photovoltaic (PV) - Wind Energy Conversion System
}

\author{
Y.Priyanka ${ }^{1}$, Dr.R.Balasubramanian ${ }^{2}$ \\ Electrical and Electronics Engineering ${ }^{1,2}$, G.Narayanamma Institute of Technology \& Science $e^{1,2}$ \\ priya.yerpula@gmail.com ${ }^{1}$, rbmanian47@gmail.com ${ }^{2}$,
}

\begin{abstract}
This paper deals with modeling and simulation of a Wind-PV hybrid generation system. Modeling of Wind Energy Conversion System (WECS) driven by a Squirrel-Cage Induction Generator (SCIG) driven by a variable speed wind turbine with back-back connected hysteresis band current controlled pulse width modulation(PWM) of IGBT based Voltage Source Converters(VSC). Modeling of the photovoltaic array based on its mathematical equation is used to interconnect the system to grid through a DC to DC converter, hysteresis band current controlled PWM of IGBT based VSC has been done. The main objective of the control algorithm for the VSC's is to achieve maximum power point tracking(MPPT) under varying wind speeds and varying solar irradiance and load variations. The main objective of the Grid Side Converter (GSC )is to be able to control the reactive power and maintain unity power factor operation. This hybrid system using WECS - PV with MPPT controllers for both are modeled and simulated in MATLAB using Simulink and Simpower system set tool boxes. The performance of this hybrid system is to show its capability of MPPT and power quality improvement.
\end{abstract}

Keywords: MPPT (Maximum Power Point Tracking), VSC (Voltage Source Converter),GSC( Grid side Converter), MSC (Machine side converter), HBPWM (Hysteresis Band Current Control Pulse Width Modulation), TSR (TIP Speed Ratio),SCIG (Squirrel Cage Induction Generator)

\section{INTRODUCTION}

Renewable energy is any energy source that is naturally replenished, like that derived from solar, wind, geothermal or hydroelectric action. Energy produced from the refining of biomass is also often classified as renewable. Coal, oil or natural gas, on the other hand, are finite sources known as Conventional energy sources but the majority of the world's energy sources come from Non- Renewable energy sources-fossil fuels such as coal, oil and natural gas and Though, the available amount of these fossil fuels are extremely enormous, but due to reduce in level of fossil fuel and oil level day by day after a few years it will end. Hence Renewable energy source demand increases as it is green friendly and pollution free which reduces the greenhouse effect. The Non -Renewable energy Sources of energy are quickly depleting and also the cost of energy is rising therefore photovoltaic Generation system and Wind energy conversion system are hopeful substitute.

Therefore our main aim is to increase the efficiency and power output of the system by incorporating Maximum Power Point tracking (MPPT) for PV Generation system and Wind energy conversion system .It is also required to model PV system and Wind energy conversion system with suitable power electronic interfacing with the grid and load under varying solar irradiance, wind speed and load variations.

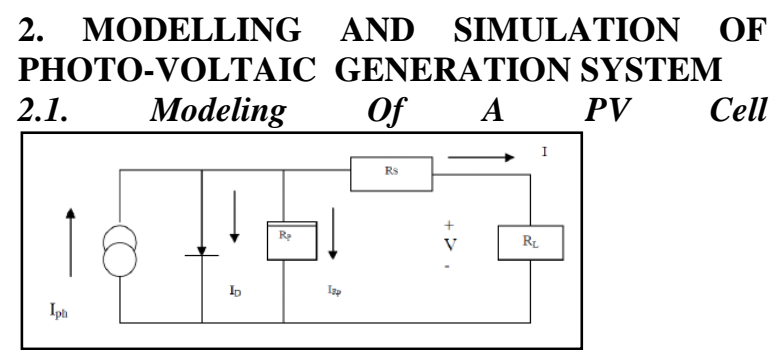

Fig1.PVcell Equivalent circuit

$\mathbf{I}_{\mathrm{ph}}=\mathbf{I}_{\mathrm{D}}+\mathbf{I}_{\mathrm{Rp}}+\mathbf{I}$

$$
\begin{gathered}
I=I_{P h}-I_{R p}-I_{D} \\
I=I_{p h}-I_{0}\left[\exp \left(\frac{v+I R s}{V T}\right)-1\right]\left[\frac{V+I R s}{R p}\right]
\end{gathered}
$$

Where $I_{P h}$ is the photo current, I is the Photo Voltaic Cell current, Io is the Dark current, $\mathrm{V}$ is the Cell voltage, $V_{T}$ is the Thermal voltage ( $\mathrm{kT} / \mathrm{q}$ ), $\mathrm{K}$ is the Boltzman constant, $\mathrm{T}$ is the Temperature $(\mathrm{K}) \mathrm{q}$ is the Charge of an electron [1]

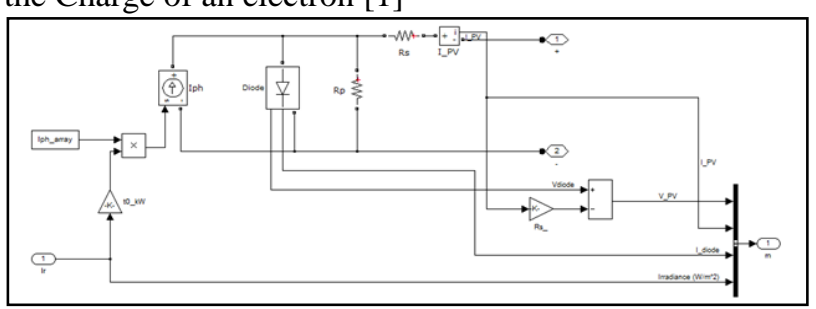

Fig.2 PV cell Simulink diagram 


\begin{tabular}{|c|l|}
\hline Parameters & Values \\
\hline $\boldsymbol{N}_{\boldsymbol{p}}$ & 11 \\
\hline $\boldsymbol{N}_{\boldsymbol{s}}$ & 3 \\
\hline $\boldsymbol{V}_{\boldsymbol{o c}}$ & $64.2 \mathrm{~V}$ \\
\hline $\boldsymbol{I}_{\boldsymbol{s c}}$ & $5.96 \mathrm{~A}$ \\
\hline $\boldsymbol{V}_{\boldsymbol{m} \boldsymbol{p}}$ & $54.7 \mathrm{~V}$ \\
\hline $\boldsymbol{I}_{\boldsymbol{m} \boldsymbol{p}}$ & $5.58 \mathrm{~A}$ \\
\hline $\boldsymbol{P}_{\boldsymbol{m} \boldsymbol{p}}$ & $305.2 \mathrm{~W}$ \\
\hline
\end{tabular}

Table 1: Parameters used in the MATLAB

2.2. PV Array Characteristic Curves: The power vs voltage characteristics for various irradiance but a fixed temperature $\left(25^{\circ} \mathrm{C}\right)$ is shown below in Figure 3 .Irradiance, temperature plays an main role in predicting the PV characteristic, and both factors have to be considered while modeling the Photo Voltaic Generation system.

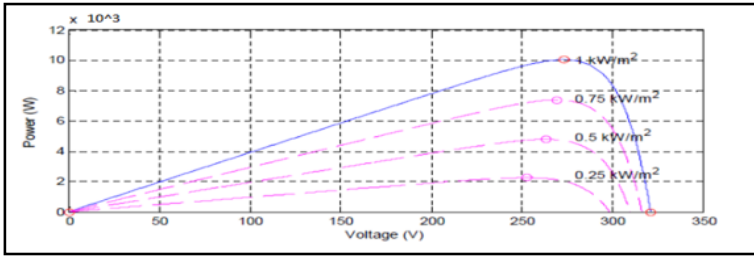

Fig.3 P-V Characteristic of a Photo-Voltaic Array for a fixed temperature but for different irradiance

2.3. Incremental Conductance Method (MPPT) With Direct Control Algorithm To Boost Converter

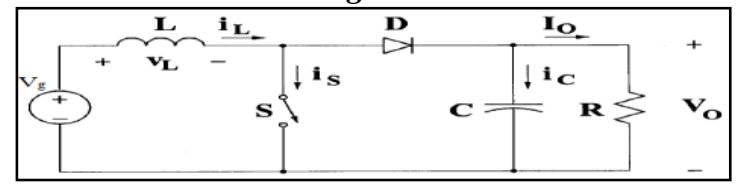

Fig .4 Circuit diagram of boost converter

In this control algorithm the array terminal voltage is always adjusted according to the Maximum Power Point(MPP) voltage. It is based on the incremental and instantaneous conductance of the Photo Voltaic module. The slope of the Photo Voltaic array power curve is zero at the Maximum Power Point( MPP), increasing on the left-hand side of the Maximum Power Point ( MPP) and decreasing on the right-hand side of the Maximum Power Point( MPP). The

\begin{tabular}{|l|}
\hline$\frac{d I}{d V}=-\frac{I}{v} \quad$ at Maximum Power \\
Point $\quad(1)$ \\
$\frac{d I}{d V}>-\frac{I}{v} \quad$ Left-hand side of \\
Maximum Power Point (2) \\
$\frac{d \mathrm{~d}}{d \mathrm{~V}}<-\frac{\mathrm{I}}{\mathrm{V}} \quad$ Right - hand side of \\
Maximum Power Point $\quad(3)$ \\
\hline
\end{tabular}

necessary equations of this control algorithm are as follows :

Where I and V are the Photo Voltaic array output current and voltage,respectively.

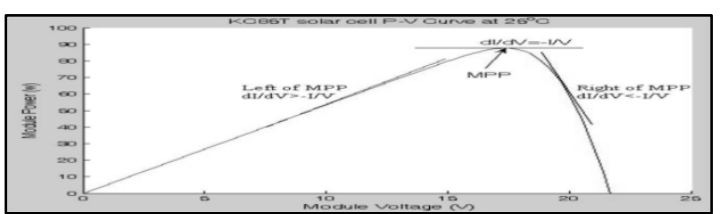

Fig. 5 Photo Voltaic (PV) module Power-Voltage Characteristics

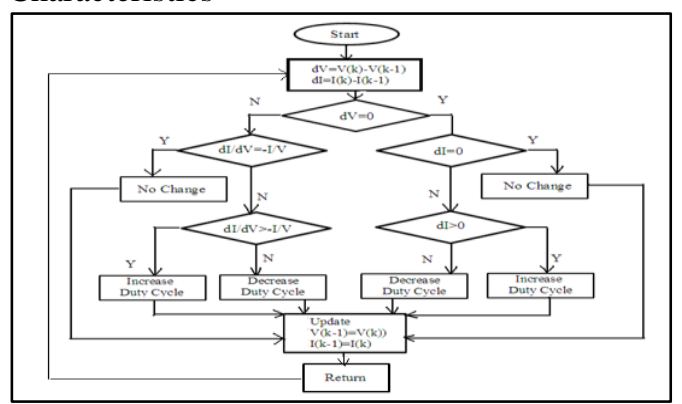

Fig.6 Incremental conductance method with direct control

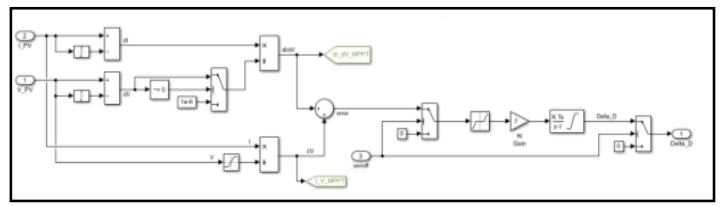

Fig.7 Incremental conductance method with direct control Simulink model

The duty cycle $(\delta)$ is calculated according to the Maximum Power Point Tracking algorithm. [6].

\section{HYSTERESIS BAND CURRENT CONTROL PWM (HBCCPWM)}

This control method is basically an instant feedback current control method of Pulse Width Modulation where the actual current constantly tracks the control current within a particular hysteresis band.

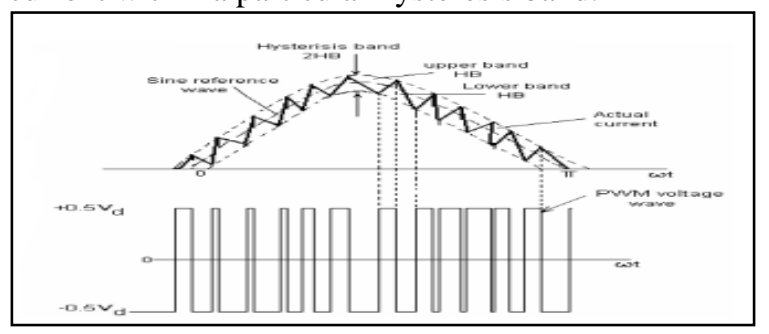

Fig. 8 Hysteresis Current Controller Operating Principle

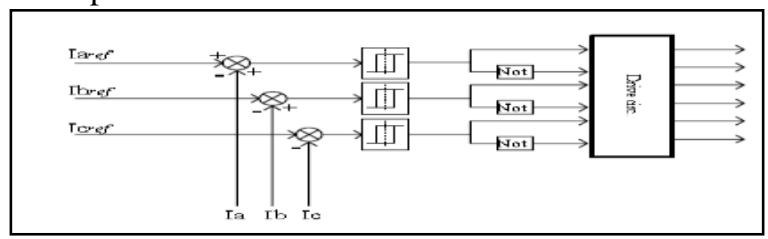

Fig.9 Hysteresis Current Controller

The hysteresis current controller generate output pulses to the inverter based on this principle i.e output pulse $=1$ when 
$\mathrm{i}_{\mathrm{p}, \mathrm{ref}}-\mathrm{i}_{\mathrm{p}}>\varepsilon$ and output pulse $=0$ when $\mathrm{i}_{\mathrm{p}, \mathrm{ref}}-\mathrm{i}_{\mathrm{p}}<-$ $\varepsilon$

Where $\mathrm{p}=\mathrm{a}, \mathrm{b}, \mathrm{c}$ phases and $\varepsilon$ is the hysteresis band .

The algorithm for this scheme is:

$\mathrm{i}_{\mathrm{p} \text {,ref }}(\mathrm{t})=\mathrm{I}_{\mathrm{p}, \text { ref }} \operatorname{Sin}(\omega \mathrm{t})$

Upper band $\mathrm{i}_{\mathrm{u}}=\mathrm{i}_{\text {pref }}(\mathrm{t})+\delta \mathrm{i}$, Lower band $\mathrm{i}_{\mathrm{l}}=\mathrm{i}_{\mathrm{p}, \text { ref }}(\mathrm{t})$

$-\delta \mathrm{i}$

Where $\delta \mathrm{i}=$ hysteresis band limit

If $i_{p}>i_{u}, V_{p o}=-V_{d c} / 2$, If $i_{p}>i_{l}, V_{p o}=V_{d c} / 2$

Else, keep at the same state. Where $\mathrm{p}=\mathrm{a}, \mathrm{b}, \mathrm{c}$ phases .[5]

\section{MODELLING AND SIMULATION OF WIND ENERGY CONVERSION SYSTEM(WECS)}

4.1 Performance of Wind Turbine: Power in Wind, $P=0.5 \mathrm{~A} \rho v^{3}$ (watts). The power of a wind turbine $P_{t}=0.5 A \rho v^{3} C_{p}(\lambda, \beta)$ where, $C_{p}$ is the power coefficient which is a function of $\lambda$, and $\beta$. $\beta$ is the pitch angle and $\lambda$ is the tip speed ratio( TSR). The power efficiency information of a Wind turbine is provided by $C_{p}(\beta, \lambda)$ performance curve.

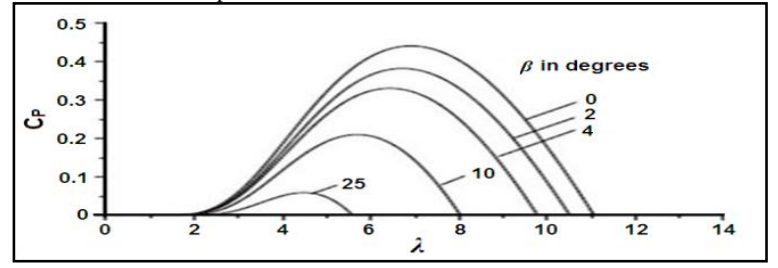

Fig.10 $C_{p}(\beta, \lambda)$ Performance curve

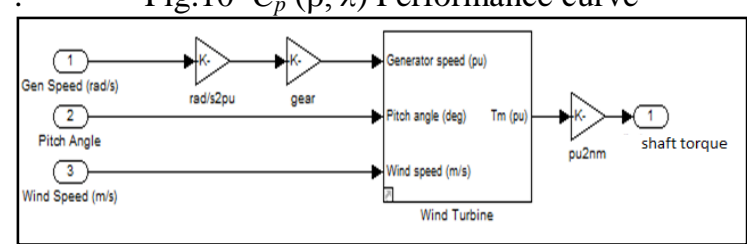

Fig 11Wind turbine Simulink block

4.2. Variable Speed WECS: They are used to achieve maximum aerodynamic efficiency over a broad range of wind speeds. With the variable speed operation, it is possible to continuously accelerate (or) decelerate the revolving speed of the Wind Turbine to the wind speed. The Variable Speed Wind Turbine is set with an induction generator and connected to the grid through power electronic converters.

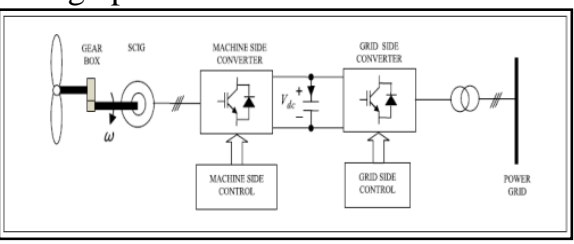

Fig. 12 Squirrel Cage Induction Generator (SCIG) based Wind Energy Conversion System

4.3. Tip Speed Ratio Control Method(TSR): In this control, the revolving speed of the generator is regulated in order to maintain the Tip Speed Ratio at its best possible value at which maximum power is extracted. i.e $\lambda(t)=\lambda_{\text {opt }}$ shaft revolving speed $\omega_{\text {lopt }}(t)$ $=\lambda_{\text {opt }} v(t) / R$. This TSR control method forces the Wind Energy Conversion System to operate at optimal regime control (ORC) by comparing the reference speed with the actual speed and giving this difference to the controller. This controller changes the speed of the generator to decrease this error[9]..

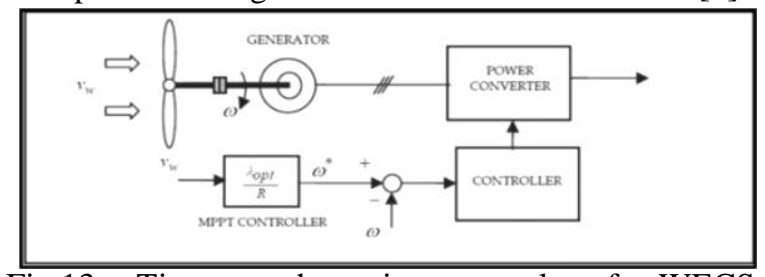

Fig.13 Tip speed ratio control of WECS

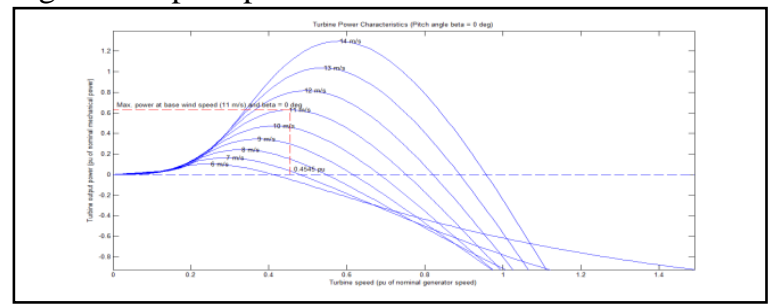

Fig.14 Wind turbine power characteristic curves

4.4. Modeling of Rotor Flux Oriented Vector Control of Squirrel Cage Induction Generator

The Electromechanical torque given as

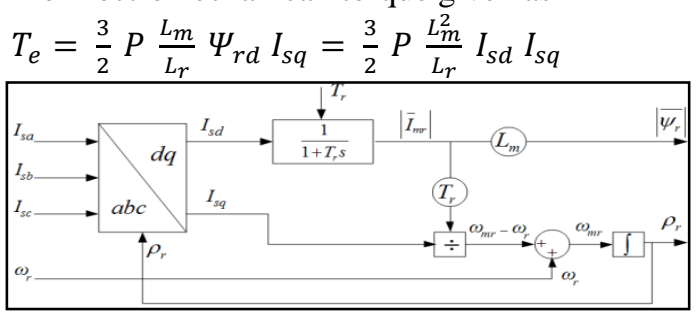

Fig 16 Flux model in rotor-flux oriented vector control

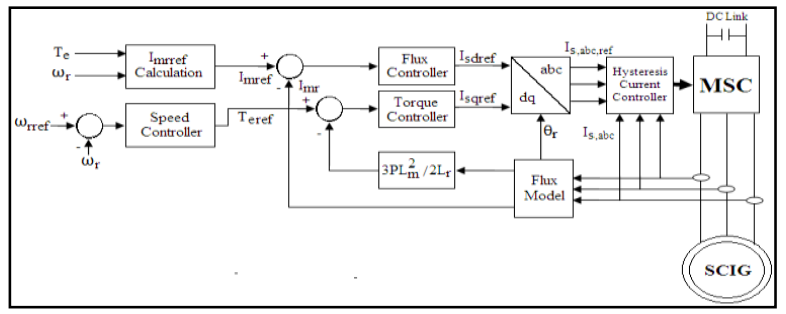

Fig 17 Indirect Execution of rotor flux oriented vector control of squirrel cage generator (SCIG)

The flux controller generates the reference d-axis current $\left(I_{s d, r e f}\right)$ and the torque controller generates the reference q-axis current $\left(I_{s q, r e f}\right)$.By hysteresis current control method a voltage source inverter is used to generate the three phase currents. $a b c$ to $d q$ transformation: 
$\left[\begin{array}{l}I_{s d} \\ I_{s q}\end{array}\right]=$

$\frac{2}{3}\left[\begin{array}{ccc}\cos \theta & \cos \left(\theta-\frac{2 \pi}{3}\right) & \cos \left(\theta+\frac{2 \pi}{3}\right) \\ -\sin \theta & -\sin \left(\theta-\frac{2 \pi}{3}\right) & -\sin \left(\theta+\frac{2 \pi}{3}\right)\end{array}\right]\left[\begin{array}{l}I_{s a} \\ I_{s b} \\ I_{s c}\end{array}\right]$

$\mathrm{d}, \mathrm{q}$ reference currents to three phase reference currents as :

$\left[\begin{array}{l}I_{\text {sa,ref }} \\ I_{s b, r e f} \\ I_{s c, r e f}\end{array}\right]=\left[\begin{array}{cc}\cos \theta & -\sin \theta \\ \cos \left(\theta-\frac{2 \pi}{3}\right) & -\sin \left(\theta-\frac{2 \pi}{3}\right) \\ \cos \left(\theta+\frac{2 \pi}{3}\right) & -\sin \left(\theta+\frac{2 \pi}{3}\right)\end{array}\right]\left[\begin{array}{l}I_{s d, r e f} \\ I_{s q, \text { ref }}\end{array}\right]$

\section{GRID SIDE CONVERTER CONTROL:}

A d-q reference frame control, uses a reference frame transformation from abc to dq, A conventional PLL is used to supervise the grid voltage angle which is used for transformation of the three phase( currents/voltages) to d-q reference frame.

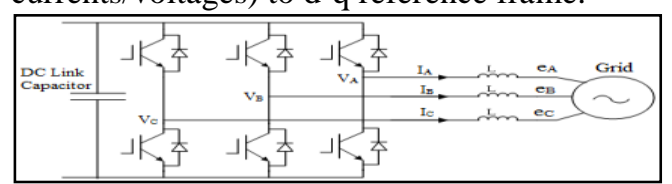

Fig.18 Grid connected Pulse Width Modulation (PWM)inverter

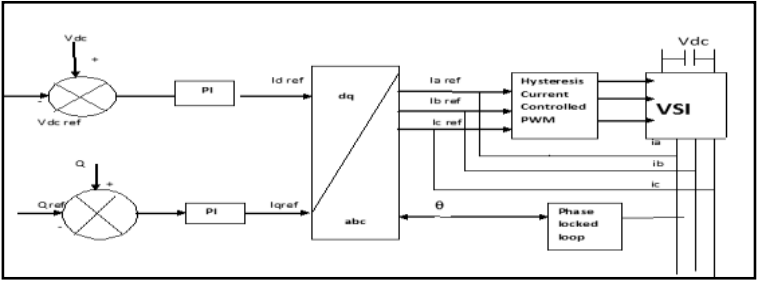

Fig.19 Grid Side Controller

The PI current controllers along the $\mathrm{d}$ and q-axes uses the control law as:

$I_{d r e f}=K_{p}\left(V_{d c, r e f}-V_{d c}\right)+K_{i} \int\left(v_{d c, r e f}-\right.$ $\left.V_{d c}\right) d t$

$I_{\text {qref }}=K_{p}\left(Q_{\text {ref }}-Q\right)+K_{i} \int\left(Q_{\text {ref }}-Q\right) d t$

Transformation of this currents to three phase currents

$\left[\begin{array}{l}I_{a, r e f} \\ I_{b, r e f} \\ I_{c, r e f}\end{array}\right]=$

$\left[\begin{array}{cc}\sin \omega t & \cos \omega t \\ \sin (\omega t-2 \pi / 3) & \cos (\omega t-2 \pi / 3) \\ \sin (\omega t+2 \pi / 3) & \cos (\omega t+2 \pi / 3)\end{array}\right]\left[\begin{array}{c}I_{d, r e f} \\ I_{q, r e f}\end{array}\right]$

Thus by controlling $I_{d}$ and $I_{q}$ current components we can control real and reactive power and the DC-link voltage is controlled to get the required real output power. ordinary PI controller is used to control DC voltage and it can be used as the reference for the active current $i_{d .}$ and another PI controller is used for setting the reactive power reference $I_{q}$ to zero at the grid interface to have unity power factor [8]

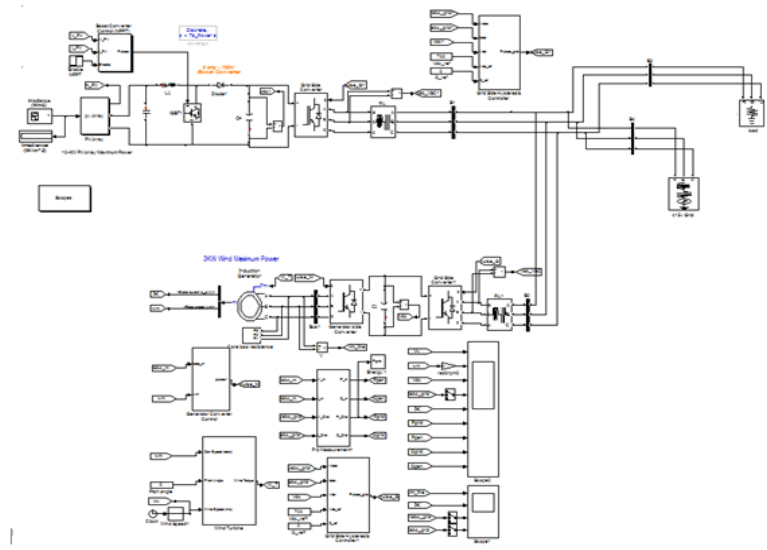

Fig.20 Simulink model for grid connected hybrid Wind -PV system

Simulation Results of Photo VoltaicGeneration System at $1000 w / m^{\wedge} 2$

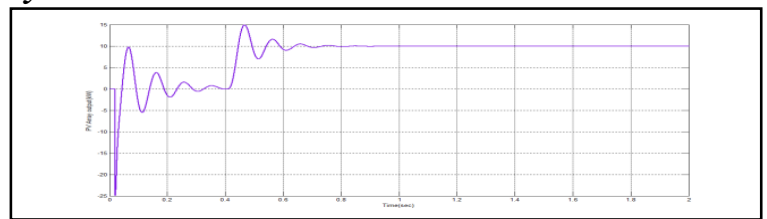

Fig (a) Photo-Voltaic Array output $(\mathrm{kW})$

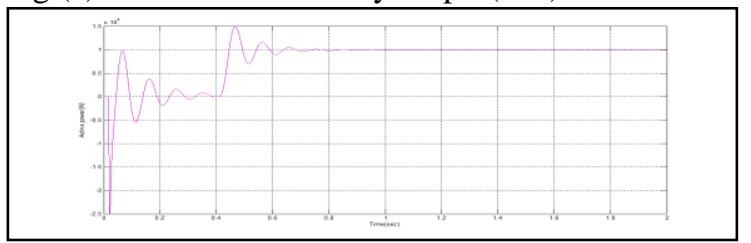

Fig (b) Active Power delivered by the Photo-Voltaic generation system $(\mathrm{kW})$

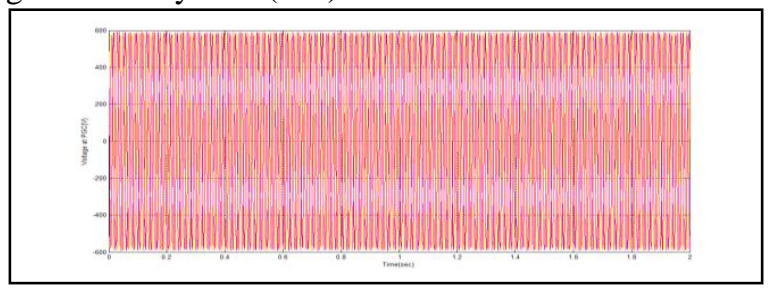

Fig (c) Voltage at the grid interconnection(V)

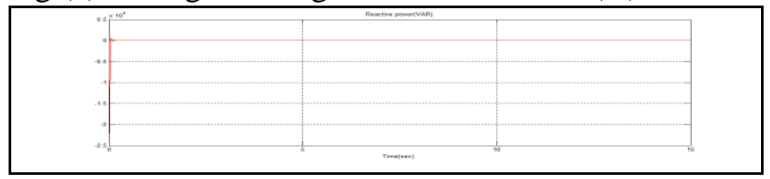

Fig (d) Reactive power is set to zero to have unity power factor

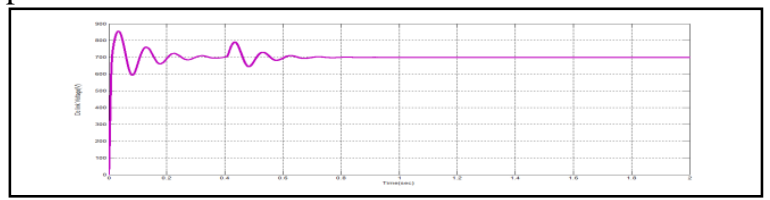

Fig (e) Constant DC link voltage across capacitor(V) 
International Journal of Research in Advent Technology, Vol.7, No.4, April 2019

E-ISSN: 2321-9637

Available online at www.ijrat.org

\begin{tabular}{|l|l|}
\hline Irradiance(KW/m^2) & $\begin{array}{l}\text { Active Power } \\
\text { Harnessed(kW) }\end{array}$ \\
\hline 0.25 & 2.5 \\
\hline 0.5 & 5 \\
\hline 0.75 & 7 \\
\hline 1 & 10 \\
\hline
\end{tabular}

Table 2: Active Power delivered at Different Irradiance by PV Generation system

The Photo-Voltaic Generation system is operated for irradiance from $0.25 \mathrm{kw} / \mathrm{m}^{\wedge} 2$ to $1 \mathrm{kw} / \mathrm{m}^{\wedge} 2$.By incorporating MPPT algorithm to boost converter we can track maximum power from PV array under various irradiance. The generated power increases with the increasing irradiance from $0.25 \mathrm{~kW} / \mathrm{m}^{\wedge} 2$ $1 \mathrm{~kW} / \mathrm{m}^{\wedge} 2$ as shown in Table 2 . Also, it is observed that generation is possible even at very low irradiance.

Simulation Results of Squirrel Cage Induction Generator(SCIG) Based Wind Energy Conversion System With Back To Back Converters

The wind energy conversion system(WECS) is operated for wind speeds ranging from $6 \mathrm{~m} / \mathrm{s}$ to 13 $\mathrm{m} / \mathrm{s}$. Initially, a wind speed of $6 \mathrm{~m} / \mathrm{sec}$ is assumed then and at every 2 seconds a step increase in wind speed is applied.

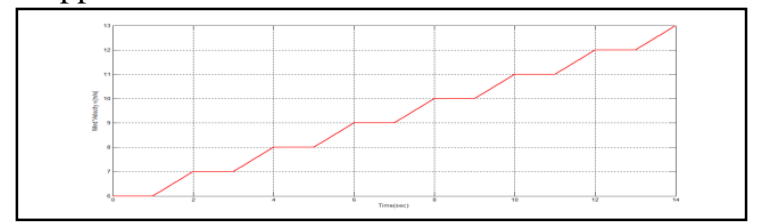

Fig. (a) Change in wind speed $(\mathrm{m} / \mathrm{s})$

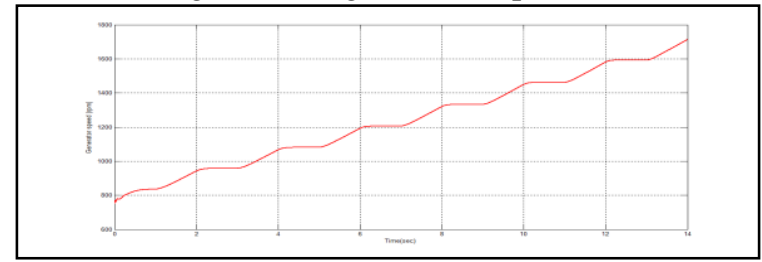

Fig. (b) Change in generator speed(rpm)

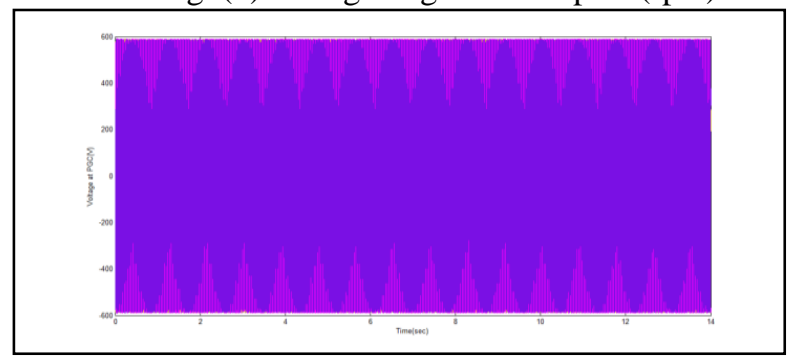

Fig.(c)Voltage at the point of grid interconnection(V)

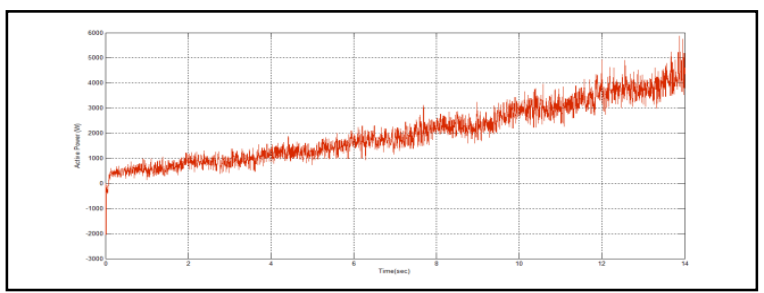

Fig. (d) Active power delivered by the Wind Energy Conversion System $(\mathrm{kW})$

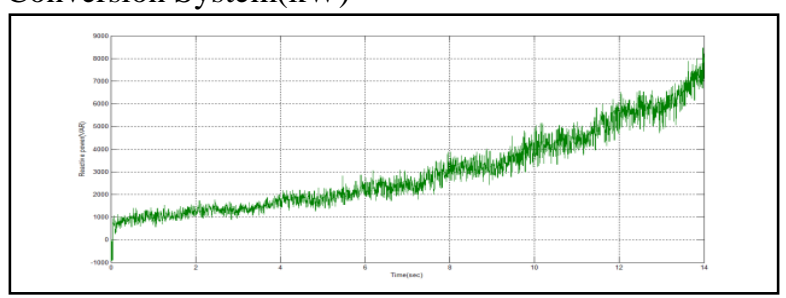

Fig. (e) Reactive power demand for SCIG

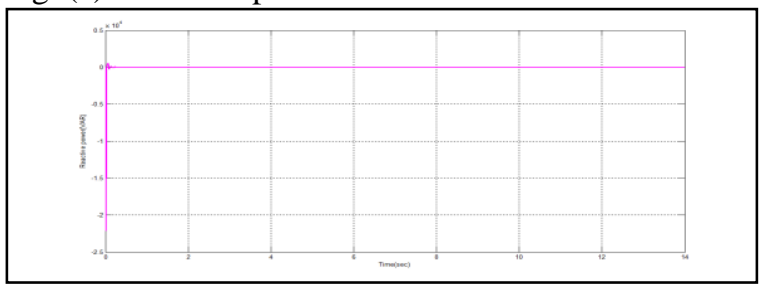

Fig. (f) Reactive power is set to zero to have unity power factor

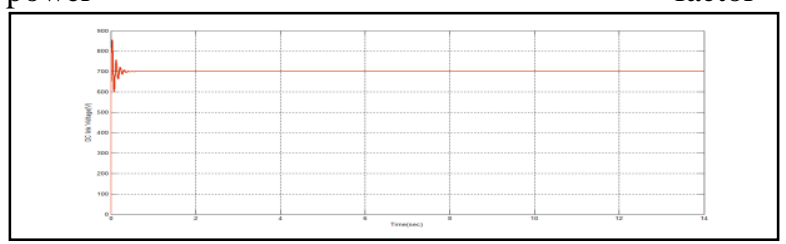

Fig. (g) Constant DC link voltage across capacitor(V)

Table 3: Active Power Harnessed at Different Wind Speeds by Wind Energy Conversion System(WECS)

\begin{tabular}{|l|l|}
\hline Wind Speed(m/s) & Active Power $(\mathbf{W})$ \\
\hline 6 & 1000 \\
\hline 7 & 1335 \\
\hline 8 & 1725 \\
\hline 9 & 2220 \\
\hline 10 & 2700 \\
\hline 11 & 3000 \\
\hline
\end{tabular}

The WECS is operated for wind speeds ranging from $6 \mathrm{~m} / \mathrm{s}$ to $11 \mathrm{~m} / \mathrm{s}$. Initially, a wind speed of $6 \mathrm{~m} / \mathrm{sec}$ is assumed which leftover for 1 second; then at every 2 seconds a step increase in wind speed is applied. The generated power increases with the increasing wind speed from $6 \mathrm{~m} / \mathrm{s}$ to $11 \mathrm{~m} / \mathrm{s}$ as shown in Table 3 . Also, it is observed that generation is possible even at very low wind speeds.

Sharing of Power Between Sources And Load For Three Different Cases 
When PV system is operated at irradiance $1000 \mathrm{~W} / \mathrm{m}^{\wedge} 2$ and WECS at wind speed $11 \mathrm{~m} / \mathrm{s}$ for three different cases sharing of power between sources and load is as follows:

\section{Simulation Results of Grid Connected Hybrid} Wind-PV System

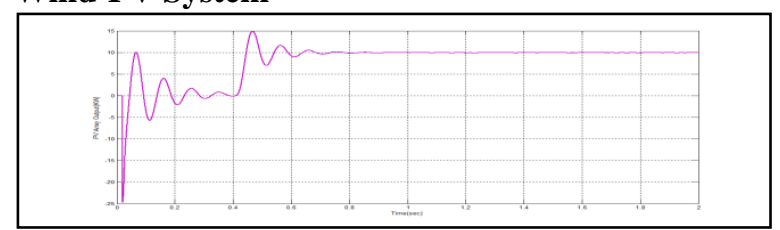

Fig. (a) PV system output(kW)

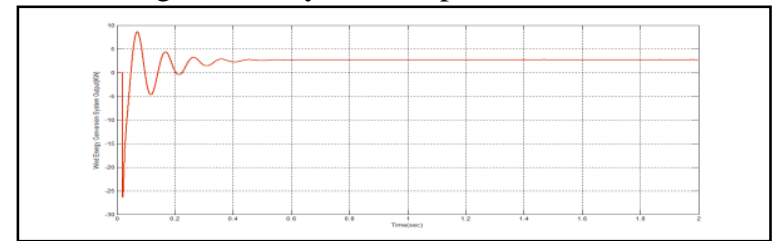

Fig. (b) WECS output(kW)

Case (1): When load demand is equal to combined output from photovoltaic and wind energy conversion system then grid will neither supply nor take power.

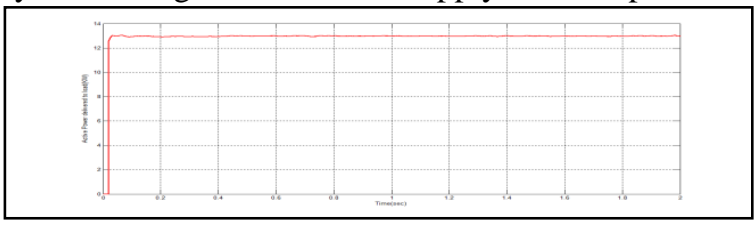

Fig.(c) Active power delivered to the load(kW)

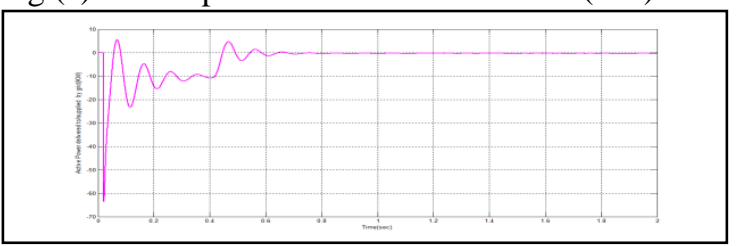

Fig. (d) Active power neither delivered to/supplied by the $\operatorname{grid}(\mathrm{kW})$

Case (2): When load demand is less than combined output from photovoltaic and wind energy conversion system power generation then surplus power generation is feed to the grid.

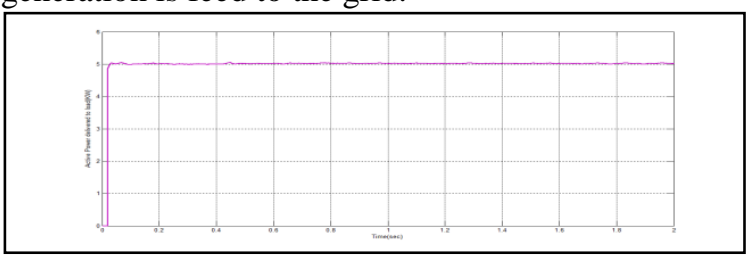

Fig (e) Active power delivered to the load $(\mathrm{kW})$

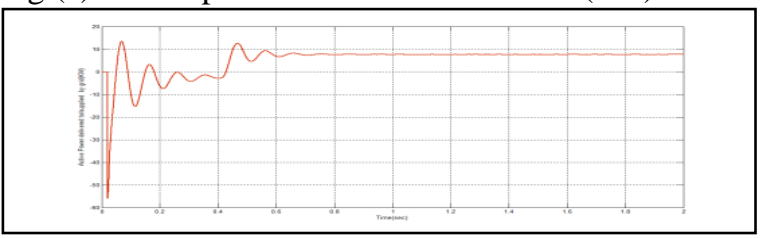

Fig. (f) Active power delivered to the $\operatorname{grid}(\mathrm{kW})$
Case (3): When load demand is greater than combined output from photovoltaic and wind energy conversion system then grid will supply remaining power to the load.

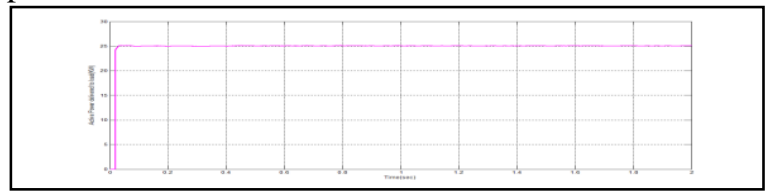

Fig. (g) Active power delivered to the load $(\mathrm{kW})$

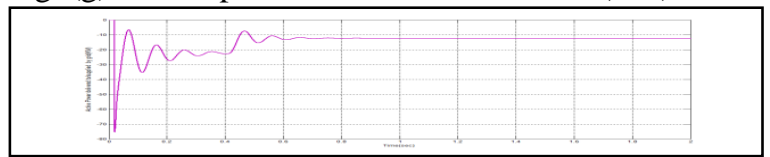

Fig.(h) Active power supplied by the grid to the load $(\mathrm{kW})$

\begin{tabular}{|l|l|l|l|}
\hline $\begin{array}{l}\text { PV } \\
\text { System }(\mathrm{kW})\end{array}$ & WECS(kW) & Load(kW) & Grid(kW) \\
\hline 10 & 3 & 13 & 0.00 \\
\hline 10 & 3 & 5 & +8 \\
\hline 10 & 3 & 25 & -12 \\
\hline
\end{tabular}

Table 4: Sharing of Power between the Sources and Load

\section{CONCLUSION}

Modeling of the photovoltaic array is used to interconnect the PV system to grid through a boost converter, hysteresis band current controlled PWM consisting of IGBT based VSC. Modeling of the wind energy conversion system (WECS) consisting of a SCIG driven by a variable speed wind turbine with back-back connected PWM consisting of IGBT based VSC has been done. Objective of this boost converter is to attain MPPT under varying solar irradiance $\left(0.25 \quad \mathbf{K W} / \mathbf{m}^{\wedge} \mathbf{2}, 0.5 \quad \mathbf{K W} / \mathbf{m}^{\wedge} \mathbf{2}, 0.75\right.$ $\left.\mathbf{K W} / \mathbf{m}^{\wedge} \mathbf{2}, 1 \mathrm{KW} / \mathbf{m}^{\wedge} \mathbf{2}\right)$, GSC is to be able to control the reactive power and keep unity power factor operation for the PV system. Objective of this MSC is to attains MPPT under varying wind speeds $(6 \mathrm{~m} / \mathrm{s}, 7 \mathrm{~m} / \mathrm{s}, 8 \mathrm{~m} / \mathrm{s}, 9 \mathrm{~m} / \mathrm{s}, 10 \mathrm{~m} / \mathrm{s}, 11 \mathrm{~m} / \mathrm{s}) \mathrm{GSC}$ is to be able to control the reactive power and maintain unity power factor operation for the WECS system. Hybrid system using PV-WECS of $13 \mathrm{KW}$ with MPPT controllers for both has been simulated in MATLAB using simulink and simpower system set tool boxes and there is power quality improvement.

\section{REFERENCES}

[1].Atiqah Hamizah Mohd Nordin; Ahmad Maliki Omar "Modeling And Simulation Of Photovoltaic (PV) Array And Maximum Power Point Tracker (MPPT) For Grid-Connected PV System”,3rd International Symposium \& 
International Journal of Research in Advent Technology, Vol.7, No.4, April 2019

E-ISSN: 2321-9637

Available online at www.ijrat.org

ExhibitionInSustainableEnergy\&Environment(ISESE

E),Page S: $114-119,2011$

[2] .D. Menniti, A. Burgio, N. Sorrentino, A.

Pinnarelli,

G.

Brusco."AnIncrementalConductanceMethodWithVar iableStepSizeforMPPT:DesignAndImplementation"

10thInternational Conference On Electrical Power Quality And Utilisation, 2009.

[3].Savitha,.Shashikala,Puttabuddhi,"ModelingofPhot ovoltaic Array And Control Of Grid Connected Photovoltaic System To Provide Quality Power To Grid", International Conference On Electrical, Electronics, Communication, Computer And Optimization Techniques, 2016

[4] M. Azizur Rahman ,Tawfik S. Radwan, Ali M. Osheiba, Azza E. Lashine "Analysis Of Current Controllers For Voltage-Source Inverter”,,IEEE Transactions On Industrial Electronics, Vol. 44, NO. 4, August 1997.

[5].AlameluNachiappan ; KSundararajan ; VMalarsel vam,"Current Controlled VoltageSource Inverter Usi ng Hysteresis ControllerandPIController",Internation alConferenceonPower,Signals, Controls AndComput ation,2012,Pages: 1 - 6,2012.

[6]Divya teja Reddy Challa and Raghuvendar,"Incremental Conductance MPPT with Direct Control with Cuk Converter", International Journal of Modern Engineering Research, 2012.

[7] Modelling And Simulation Of A Hysteresis Band Pulse Width Modulated Current Controller Applied To A $\quad$ Three PhaseVoltageSourceInverterByUsingMatlab,B.Venk ataRanganadh,A.Mallikarjuna Prasad, Madichetty Sreedhar

[8]F.Blaabjerg,R.Teodorescu,M.liseree,andA.V.Timb us :overview of control and grid synchronization for distributed power generation systems,"IEEE Transactions on industrial electronics, vol 53,No.5,October 2006

[9] T.Ahmed, K.Nishida and M.Nakaoka, "MPPT Control Algorithm for Grid Integration of Variable Speed Wind Energy Conversion System" IEEE $35^{\text {th }}$ Annual Conference on Industrial Electronics IECON 2009, pp. 645-650.

[10] Majid A. Abdullah, A.H.M. Yatim , Chee wei and Tan , "A Study of Maximum Power Point Tracking Algorithms for Wind Energy System" IEEE First Conference on Clean Energy and Technology - CET 2011, pp.321 -326. 